\title{
Estado social y medio ambiente
}

\section{Ángel B. Gómez Puerto'}

Resumen: Los dos últimos años de la segunda década del siglo XXI han supuesto, sin lugar a duda, la vuelta a la agenda institucional y política de la preocupación por la protección del medio ambiente. En este contexto global favorable, desde el Derecho hemos de impulsar estudios académicos y propuestas para que se implementen los instrumentos jurídicos y organizativos a fin de seguir avanzando en dicha necesaria protección, con la imprescindible implicación de la ciudadanía.

En este trabajo el autor hace un repaso del contexto global de la protección del medio ambiente, aterrizando en nuestra arquitectura constitucional sobre la materia, enmarcando la protección del medio ambiente como un contenido esencial de la fórmula constitucional Estado social y democrático de derecho. Pretende ser una aportación académica a la necesaria concienciación e implicación ciudadana.

Palabras clave: Medio ambiente, Estado social, Constitución, implicación, ciudadanía.

Fecha de recepción: I de abril de 2020.

Fecha de admisión definitiva: 21 de julio de 2020.

\section{Social Status and Environment}

Abstract: Concern for the protection of the environment has, without a doubt, made a comeback on the institutional and political

\section{Statut Sociale et Environnement}

Résumé: Les deux dernières années de la deuxième décennie du XXle siècle ont, sans aucun doute, vu un retour à l'ordre du jour

' Área de Derecho Constitucional. Departamento de Derecho Público y Económico. Universidad de Córdoba.bgomez@uco.es 
agenda during the last two years of the second decade of the 21 st century. Counting on the essential participation of citizens, we must take advantage of this favourable global context and take a legal approach to promote academic studies and proposals for the implementation of legal and organisational instruments in order to continue making progress in such a crucial area.

In this study, the author reviews the global context of environmental protection as well as our own constitutional architecture in this area, and presents environmental protection as an essential element of the constitutional formula for the social and democratic rule of law. The aim of this work is to serve as an academic contribution to help raise the necessary awareness and involvement of citizens.

Key words: Environment, welfare state, constitution, involvement, citizenship. institutionnel et politique de la préoccupation pour la protection de l'environnement. En comptant sur la participation essentielle des citoyens, nous devons profiter de ce contexte mondial favorable et adopter une approche juridique pour promouvoir des études universitaires et des propositions de mise en œuvre $d$ 'instruments juridiques et organisationnels afin de continuer à progresser dans un domaine aussi crucial.

Dans ce travail l'auteur passe en revue le contexte mondial de la protection de l'environnement, révise notre architecture constitutionnelle en la matière, et présente la protection de l'environnement comme un élément essentiel de la formule constitutionnelle de l'état de droit social et démocratique. Le but de cet œuvre est de servir de contribution académique à la sensibilisation et l'implication indispensable des citoyens.

Mots clé: L'environnement, l'état social, constitution, implication, citoyenneté.

\section{Protección del medio ambiente a nivel universal. Evolución histórica}

Durante la primera década del siglo XXI y buena parte de la segunda, se ha hablado muy poco de la importancia de proteger los valores ambientales. La crisis económica, sus causas y sus consecuencias provocó el olvido de cuestiones como el medio ambiente. No obstante, en el año 2019 se ha reactivado el debate y el interés por la protección global del medio ambiente, sobre todo desde que en la segunda parte del año 2018 se iniciara un movimiento juvenil (los viernes por el futuro) para reclamar un cambio, un mayor compromiso de los Estados contra el cambio climático, con la joven estudiante sueca Greta Thunberg convertida en icono global.

\section{Como afirma la profesora Sagrario Morán Blanco (Morán, 2012),}

el siglo XXI despertó con tres grandes amenazas: la pobreza, la violencia-generada por la guerra, la delincuencia organizada y el terrorismo- y el cambio climático. Los tres fenómenos, catapultados a la consideración de desafíos globales, no quedan retenidos en las fronteras sino que afectan en mayor o menor medida a todos los países del mundo, 
y recuerda unas palabras de 2007 del ex Secretario General de las Naciones Unidas, Kofi Annan que advirtió que

el impacto humanitario del cambio climático probablemente sea uno de los mayores retos humanitarios durante los próximos años y décadas,

como se ha confirmado con lo que está aconteciendo en los últimos años de la segunda década del siglo XXI.

Pero, hagamos historia de esta preocupación global por el medio ambiente. Será a partir de la cumbre de Naciones Unidas de Estocolmo de 1972, y, sobre todo, tras la Cumbre de Río de 1992, cuando las políticas medioambientales y las normas jurídicas de protección experimentaron un avance notable, que lamentablemente en la primera década y parte de la segunda del presente siglo habían caído bastante en el olvido, como hemos expresado.

Un concepto clave en el compromiso global por el entorno es el de desarrollo sostenible. El libro "Nuestro Futuro Común" (Brundtland, 1987), que lideró la ex Primera Ministra de Noruega Gro Harlem Brundtland, constituyó el primer intento de eliminar la confrontación entre desarrollo y sostenibilidad.

La generación de la preocupación social por la protección del medio ambiente, y la incorporación de esta nueva demanda social y sentimiento colectivo en los ordenamientos jurídicos occidentales se producen durante el siglo XX, sobre todo en su segunda mitad, como hemos apuntado. La toma de conciencia sobre el grado de deterioro de los recursos naturales hizo necesario que los ordenamientos jurídicos nacionales e internacionales se enfrentaran al dilema entre desarrollo económico de los territorios y la protección del medio ambiente.

En este proceso histórico, un punto de inflexión determinante lo constituyó la celebración de la Conferencia de Naciones Unidas sobre Medio Ambiente Humano que tuvo lugar, como hemos dicho, en Estocolmo, en el año 1972. A partir de esta fecha, sobre todo en el ámbito de las instituciones de las entonces Comunidades Europeas, se inicia una intensa labor de elaboración y aprobación de normas de protección ambiental que determinará de forma notable el cambio de los ordenamientos jurídicos de los Estados en materia ambiental, así como el inicio de un cambio social en cuanto a la sensibilización ciudadana hacia el medio ambiente.

También, entre final de los años sesenta y principios de los setenta, se promueven, a través del Pacto Internacional de Derechos Económicos, Sociales y Culturales, los llamados Derechos Humanos de Tercera Generación, entre los que se encuentra 
el derecho al medio ambiente, como un derecho inherente a la persona y con el objetivo del progreso social y elevación del nivel de vida de todos los pueblos.

Precisamente, nuestra Constitución de 1978 se aprueba pocos años después y está inmersa en este nuevo escenario internacional y europeo, aunque todavía no éramos Estado miembro de las Comunidades Europeas. Por tanto, la introducción del artículo 45 en nuestra Constitución, formulado como derecho al medio ambiente y deber de conservar el entorno, con rango de principio rector de la política económica y social, hay que leerlo e interpretarlo en ese nuevo contexto político y jurídico internacional favorable a lo ambiental y en el marco del nuevo constitucionalismo social del momento.

En la evolución histórica de la protección jurídica del medio ambiente es central el papel de la Unión Europea, que supuso la adaptación jurídico-ambiental de España con su incorporación en enero de 1986. Con la vigencia de las normas ambientales comunitarias, estatales y autonómicas, se generó en nuestro Estado una compleja trama de normas y políticas ambientales. Como afirma el profesor López Ramón

la política ambiental de la Comunidad Europea introdujo aire fresco, mecanismos renovadores, en las anquilosadas posturas sobre el medio ambiente de nuestras regulaciones tradicionales, obligando a actuar a las administraciones públicas españolas en términos más efectivos (López, 2018).

En este escenario competencial, las Comunidades Autónomas y las Administraciones Locales están siendo determinantes tanto en la generación de nuevas normas, como en la ejecución de medidas tendentes a conseguir los objetivos constitucionales de protección del medio ambiente.

Desde esta perspectiva universal, otro elemento a considerar es la relación existente entre la protección del medio ambiente a nivel global y el respecto a los Derechos Humanos, como ha puesto de manifiesto Adriana Espinosa González en su Tesis Doctoral, en cuyo capítulo introductorio aporta la siguiente afirmación de un grupo de expertos independientes de Naciones Unidas como motivo de la celebración del Día de la Tierra en 2013:

es hora de que tomemos la ocasión de este día para reconocer el vínculo entre un medio ambiente limpio y sano y la realización de una amplia variedad de derechos humanos fundamentales [...] Continuamos fracasando en la protección y conservación del medio ambiente en numerosos aspectos, con frecuencia con graves consecuencias para el disfrute de los derechos humanos (Espinosa, 2015). 
En este proceso histórico es muy importante el año 2015, con dos acontecimientos globales de capital trascendencia, ante la evidencia científica de los graves problemas ambientales que nos amenazan. Uno de ellos fue la cumbre de París sobre cambio climático, cuyas medidas están en fase de desarrollo con demasiada lentitud y a la que nos referiremos más adelante. El otro acontecimiento lo comentamos a continuación.

En ese año 2015, se produce un hecho absolutamente inédito. La Iglesia Católica, a través del Papa Francisco, se pronuncia sobre el medio ambiente, en la Encíclica Laudato $\mathrm{Si}^{\text {" }}$ "Sobre el cuidado de la casa común", documento vaticano en que se llega a afirmar

hago una invitación urgente a un nuevo diálogo sobre el modo como estamos construyendo el futuro del planeta. Lamentablemente, muchos esfuerzos para buscar soluciones concretas a la crisis ambiental suelen ser frustrados no sólo por el rechazo de los poderosos, sino también por la falta de interés de los demás.

En las jornadas que se celebraron en octubre de 2017 en Bilbao, bajo el título Nuevas Perspectivas del Derecho ambiental en el SigloXXI, quedó de manifiesto que

comienzan a abrirse paso temas que exigen una reflexión sobre su génesis y la influencia que pueden tener en los procesos de decisión de las autoridades públicas y, en definitiva, en los ciudadanos en general, como sucede con el derecho a la alimentación o habría que decir a una alimentación que interiorice sus consecuencias para el medio ambiente, como también sucede con los organismos modificados genéticamente. A lo anterior se une la regulación del Derecho sobre las catástrofes naturales en un mundo que parece avanzar ciegamente a una realidad dominada por el cambio climático, resistiéndose a expresar compromisos concretos, como sucede con el denominado Acuerdo de París de 2015 (Bolaño, 2018).

Por último, en este recorrido, como hemos apuntado, en agosto de 2018, ante la parálisis casi de la voluntad de los Estados para dar cumplimiento a los acuerdos de París, en Suecia se inicia el movimiento de la juventud mundial a favor de la lucha frente al cambio climático, con la estudiante Greta Thunberg como "portavoz" mundial, los viernes por el futuro, que tuvo su culminación en la huelga mundial por el clima en septiembre de 2019, coincidiendo con la nueva cumbre de Naciones Unidas celebrada en Nueva York.

Afortunadamente, el medio ambiente está de nuevo en la agenda política e institucional, gracias sobre todo a que la sociedad civil, la gente joven en especial, los científicos que con sus datos han evidenciado los problemas sin resolver, las personas que con compromisos e iniciativas ciudadanas han mantenido acciones de información y concienciación, y también gracias al compromiso de muchas 
ciudades con políticas locales determinadas por el medio ambiente. Otro hito muy importante que evidencia que el medio ambiente ha entrado con empuje en la agenda política ha sido la declaración de emergencia climática del Parlamento Europeo, aprobada en 2019 o el "Pacto Verde Europeo", que propugna la presidenta de la Comisión Europea, Úrsula Von Der Leyen.

La consecuencia histórica, política y jurídica de este proceso ha sido la vigencia en la actualidad de un cuerpo normativo ambiental amplio en diversos, cada vez más, Estados de la Tierra, así como unas estructuras administrativas ambientales especializadas, con el reto común de garantizar el cumplimiento efectivo de dichas normas, para lo cual es estratégico contar con la implicación y la participación de la sociedad, así como de los colectivos implicados. Esperemos que todo este nuevo compromiso se traduzca en un cambio de tendencia global, y los seres humanos empecemos a cuidar de verdad a nuestro bien común medioambiental, no tenemos un planeta $B$ como dicen nuestros jóvenes. Necesitamos que la protección del medio ambiente sea un valor ético, un compromiso personal, una nueva solidaridad con los bienes comunes que nos rodean.

Y es que, como afirmó el profesor Ángel Valencia Saiz en un trabajo de 2018, "lo medioambiental ha dejado de ser patrimonio del ecologismo" (Valencia, 2018). Idea que es perfectamente coherente con el proceso histórico que acabo de escribir, de toma de conciencia global en torno a la necesaria protección de los valores ambientales y activismo de la sociedad civil, superando al asociacionismo ecologista y a los partidos políticos "verdes".

Es obvio que es tiempo de actuar (lema de la Conferencia de Madrid de diciembre de 2019), pues, como recientemente escribía la profesora Alba Nogueira López, catedrática de Derecho Administrativo de la Universidade de Santiago de Compostela, en su diagnóstico, que considero un diagnóstico muy acertado y sintético,

vivimos en tiempos de urgencia ambiental. La finitud de los recursos naturales, el deterioro ambiental creciente, el impacto evidente del cambio climático, patrones de consumo insostenibles y la destrucción de los ecosistemas muestran que es necesario caminar hacia un cambio de modelo que haga viable la continuidad del planeta y de las especies que en el vivimos (Nogueira, 2019).

Evidentemente estamos en un tiempo nuevo, el grado de conciencia ambiental de la ciudadanía es creciente, y parece que también el de los poderes públicos. La situación mundial no admite más demoras en la toma de decisiones y en la aportación de recursos para una protección estricta de los valores del entorno, de nuestra propia vida. 


\section{La protección constitucional del medio ambiente. Elementos conceptuales e ideas fuerza}

Con carácter previo a adentrarnos en desentrañar la configuración constitucional de la protección del medio ambiente, es conveniente algunas notas sobre el concepto de medio ambiente. A diferencia del inglés ("environment"), el francés ("environnement") o el alemán ("Umwelt"), en castellano son dos palabras las que conforman el concepto, medio y ambiente, es decir, el entorno en el que se desarrolla la vida.

La expresión medio ambiente o medioambiental empezó a formar de nuestro uso habitual en las últimas décadas del siglo XX. Actualmente se encuentra absolutamente arraigada, es muy frecuente su empleo en diferentes ámbitos ciudadanos, políticos y académicos, especialmente en los últimos dos años de la segunda década del siglo XXI. Siguiendo a la profesora de la Universidad Complutense, Inés Ibáñez Méndez

en los últimos años hemos asistido a una auténtica revolución social, que ha desembocado en una crisis de civilización a escala global. La asunción de los valores ambientales por la sociedad también ha supuesto la transformación de la concepción del Medio Ambiente. Reviste una mayor complejidad al tener que ser considerado desde una doble óptica; pública y privada. Tradicionalmente los problemas ambientales eran tratados desde un punto de vista privado, como afectante al patrimonio de las personas o a problemas de salubridad. Posteriormente los Poderes Públicos van a ir involucrándose primero mediante la -protección del dominio público y después por la protección del Medio Ambiente (lbáñez, 2003).

Como nota doctrinal de interés, el profesor Terol Becerra nos trae el pensamiento de Kelsen de la relación entre la sociedad y la naturaleza. Según este profesor,

a Kelsen, como enseguida se verá, la relación de los pueblos primitivos con los elementos de la naturaleza era de índole social.

Para Kelsen, además, la relación del hombre primitivo con la naturaleza nada tenía que ver con la idea de una conexión objetiva entre hechos, esto es, con la presunción de un nexo causal producido por fuerzas impersonales, sino que se asentaba sobre la idea de una conexión entre dos personas, esto es, sobre la suposición de una relación social que poseía un pronunciado carácter normativo (Terol, 2009).

A continuación, Terol afirma una idea importante,

además de destacar la enorme importancia que las sociedades contemporáneas conceden al medio ambiente, interesa llamar la atención sobre las dificultades que, sin impedir su análisis desde una perspectiva jurídica, pues tal es el objetivo que aquí se persigue, sin duda lo entorpecen. No es porque falten fuentes documentales bibliográficas, normativas - jurisprudenciales o porque su consulta sea problemática. Los inconvenientes proceden del objeto de estudio mismo. De la complejidad que reviste su conceptuación. 
Por su parte, expresa el profesor Francisco López Menudo,

el uso progresivo de la expresión medio ambiente ha sido directamente proporcional al incremento acelerado de los ataques a la Naturaleza habidos en los últimos años (deforestación, erosión de suelos, perturbación de la capa de ozono, cambio climático, deshielo de los círculos polares, extinción de la fauna, agotamiento de las energías no renovables, etc) y a la concienciación, prácticamente generalizada, de la imperiosa necesidad de proteger el planeta (López, 2005).

Prosigue el autor expresando que

esta sensibilidad nos parece mucho más franca en el plano de la convicción de cada individuo aislado que en el de los grupos o sistemas (en los que se integran los individuos mismos) llamados a corregir efectivamente la situación desde la responsabilidad política y desde la moderación de los intereses económicos.

En relación a los intereses económicos, legitimados según el autor en base al "progreso" y al "bienestar", constituyen en la actualidad "un azote a la Naturaleza sin precedentes".

En este marco conceptual previo, quiero también dejar presentes unas palabras pronunciadas por el Profesor Juan Ignacio Font Galán, en su lección de despedida, al que tuve el honor de asistir en el Salón de Grados de la Facultad de Derecho de la Universidad de Córdoba en septiembre de 2018:

la Encíclica Laudato Sí (Papa Francisco) identifica como parte fundamental de este patrimonio común de la humanidad el medio ambiente. Ningún título de propiedad puede jamás dañarlo. No se trata solo del no robarás, sino también del no matarás cuando, en daño del ecosistema, se pone en riesgo las vidas de las personas del hoy y del mañana, así como la buena conservación de la casa común.

El texto íntegro de la lección fue publicado unos meses después (Font, 2019).

Siguiendo con estos elementos conceptuales previos en torno al medio ambiente, dado que el artículo 45 CE no define qué es medio ambiente, lo hizo el Tribunal Constitucional en 1995 (STC 120/1995), integrando en el medio ambiente, desde una perspectiva jurídica, a los recursos naturales, la flora y la fauna, los animales y los vegetales o plantas, los minerales, los tres reinos clásicos de la Naturaleza con mayúsculas, en el escenario que suponen el suelo y el agua, el espacio natural. Sin embargo, considera el alto Tribunal,

el paisaje, que no es sólo una realidad objetiva sino un modo de mirar, distinto en cada época y cada cultura... Se trata de un concepto estructural cuya idea rectora es el equilibrio de sus factores, tanto estático como dinámico, en el espacio y en el tiempo.

Más adelante profundizaremos en la interpretación del TC de nuestro artículo 45CE. 


\section{En esa misma resolución, el Tribunal Constitucional afirmó que}

el ambiente es un concepto esencialmente antropocéntrico y relativo. No hay ni puede haber una idea abstracta, intemporal y utópica del medio, fuera del tiempo y del espacio, es siempre concepción concreta, perteneciente al hoy y operante aquí.

\section{Como señala Terol Becerra,}

la STC 102/1995 ha servido de pauta a un buen número de resoluciones jurisprudenciales posteriores caracterizadas por revalidar, con absoluta fidelidad, la noción de medio ambiente allí formulada. No en balde acabará esa idea operando en ellas como premisa de la respuesta a la contienda competencial que, en cada caso, afrontan. Circunstancia ésta que anima a juzgarlas conformadoras de un ciclo que, inaugurado por aquella, integra también a las SSTC 163/1995, 196/1996, 16/1997, 28/1997, 14/1998, 15/1998,40/1998, 110/1998 y 195/1998, casi todos los pronunciamientos que, luego de la inicial STC 102/1995 y hasta la fecha, ponen fin a controversias entre el Estado y las Comunidades Autónomas relacionadas con el medio ambiente (Terol, 2010).

El Tribunal Supremo también se ha pronunciado sobre el concepto de medio ambiente en un asunto penal (STS 53/2003) afirmando que

en cuanto el art. 45 de la Constitución dispone que todos tienen derecho a disfrutar de un ambiente adecuado para el desarrollo de la persona, parece que la figura delictiva debe orientar su protección y fijar su atención prioritaria en la salud de las personas, aunque nadie discute que la protección alcanza, de manera directa o indirecta, a la fauna, la flora y los espacios naturales.

Por su parte, pero ya definiendo al Derecho Ambiental en general, Silvia Jaquenod Zsogon la entiende como

la disciplina jurídica que investiga, estudia y analiza las diferentes relaciones entre los bienes naturales y la actividad antropocéntrica, orientando la regulación jurídica de las conductas y actitudes humanas respecto al uso, explotación y aprovechamiento de recursos naturales, conservación de la Naturaleza y protección del ambiente (Jaquenod, 1996).

En sus inicios, como mantiene la profesora de Derecho Internacional Público Rosa Fernández Egea

la protección de los bienes ambientales concernía al derecho inter-privatos, es decir, el derecho civil. El medio ambiente preocupaba en la medida que suponía una merma económica para alguien. Por ejemplo, la tala de árboles, la matanza de animales, la contaminación de un lago o río, todos estos daños ambientales no preocupaban por su valor intrínseco, sino por el perivicio económico causado a sus propietarios (Fernández, 2015).

Por su parte, el profesor de Derecho Administrativo Francisco Velasco Caballero con relación al concepto constitucional de medio ambiente, que 
en el proceso de elaboración del art. 45 CE se puede observar una clara tendencia antropocéntrica en la protección del medio ambiente. También en la jurisprudencia judicial - muy condicionada por fenómenos de contaminación urbana, y especial del ruido- se observa con claridad la tendencia antropocéntrica ya comentada.

$Y$ añade que

la STS (Penal) 53/2003 establece que en cuanto el art. 45 de la Constitución dispone que todos tienen derecho a disfrutar de un ambiente adecuado para el desarrollo de la persona (...) parece que la figura delictiva debe orientar su protección y fijar su atención prioritaria en la salud de las personas, aunque nadie discute que la protección alcanza, de manera directa o indirecta, a la fauna, la flora y los espacios naturales.

En ese mismo trabajo del profesor Velasco Caballero, se nos recuerda que en los debates constituyentes

el medio ambiente siempre apareció vinculado al desarrollo de la persona o de la personalidad (Velasco, 2018).

También sobre el objeto conceptual de medio ambiente protegido constitucionalmente, el profesor Agustín Ruiz Robledo,

la imagen que se tiene hoy del medio ambiente es amplia, referida tanto a la biosfera (aire, agua y suelo) como a los ecosistemas producto de la interacción entre seres vivos (flora y fauna). Ahora bien, parece excesivo considerar en España que la Constitución avale el concepto omnicomprensivo italiano (Ruiz, 1993).

Este autor también destaca de la regulación constitución de la materia el carácter teleológico, finalista, inserto en la expresión "para el desarrollo de la persona", considerando también esencial el papel que se otorga en nuestro artículo 45 a los poderes públicos en la protección del medio ambiente.

El profesor Ramón Martín Mateo, "padre" del Derecho Ambiental en nuestro país, manifiesta que

una aproximación al concepto de medio ambiente nos remite a una noción amplia que incluye toda la problemática general y, por supuesto, el tema capital de la utilización de los recursos a disposición del hombre en la biosfera (Martín, 2003),

apostando por un concepto amplio de medio ambiente en la línea de las principales declaraciones internacionales.

El propio Tribunal Constitucional (STC 64/1982), pocos años después de promulgada la Constitución, con relación a la expresión medio ambiente, la consideraba una expresión gramaticalmente redundante y calificable jurídicamente, a su juicio, 
como "concepto jurídico indeterminado con un talante pluridimensional y, por tanto, interdisciplinar. En todo caso, desde una perspectiva semántica, hemos de destacar la acepción del Diccionario de la Real Academia que define al "medio" como el "conjunto de circunstancias culturales, económicas y sociales en que vive una persona o un grupo humano".

Por último, sobre estas cuestiones conceptuales, es muy ilustrativa la Declaración de la Conferencia de las Naciones Unidas sobre el Medio Ambiente Humano (junio 1972), al proclamar en su Preámbulo que

el hombre es a la vez obra y artífice del medio que lo rodea, el cual le da el sustento material y le brinda la oportunidad de desarrollarse intelectual, moral, social y espiritualmente. En la larga y tortuosa evolución de la raza humana en este planeta se ha llegado a una etapa en que, gracias a la rápida aceleración de la ciencia y la tecnología, el hombre ha adquirido el poder de transformar, de innumerables maneras y en una escala sin precedentes cuanto le rodea. Los dos aspectos del medio humano, el natural y el artificial, son esenciales para el bienestar del hombre y para el goce de los derechos fundamentales, incluso el derecho a la vida misma.

Dos décadas después, en la Declaración de Río (Cumbre de la Tierra, 1992), se afirmaba el concepto de "naturaleza integral e interdependiente de la Tierra, nuestro hogar".

\section{La obligación constitucional de conservar el medio ambien- te como contenido del Estado Social. Propuestas de reforma constitucional}

Nuestra Constitución, en el primero de sus artículos define a España como Estado social. Y que en el artículo 9.2 se expresa la cláusula social de nuestro Estado, con especiales encomiendas a los poderes públicos. El profesor Agudo Zamora, nos recuerda el concepto de Estado social (o de bienestar) de A. Briggs como

el poder organizado y usado deliberadamente a través de la política y la administración en un esfuerzo para modificar el juego de las fuerzas del mercado al menos en tres direcciones: primera para garantizar a los individuos y familias una renta mínima independientemente del valor del mercado de su trabajo o propiedad; segundo, reducir la amplitud de la inseguridad para facilitar a individuos y familias satisfacer ciertas contingencias sociales que de lo contrario conducen a crisis individuales y familiares; y tercero, para asegurar que a todos los ciudadanos sin distinción de status o clase les sean ofrecidos los mejores estándares disponibles en relación a cierta gama acordada de servicios sociales (Agudo, 2017). 
Así,

el Estado de bienestar supone un nuevo campo de acción que lleva a que el Estado abandone su actitud pasiva o abstencionista (típicamente liberal) con el objetivo de regular y orientar el proceso económico, convirtiéndose en un Estado prestacional, encuadrándose en una dinámica de protección a la sociedad (Agudo, 2013).

El Estado social se responsabiliza, por tanto, de la procura existencial, concepto acuñado por Forsthoff como nos recuerda Agudo Zamora, y que supone, como señala García Pelayo, la responsabilidad por parte del Estado de "llevar a cabo las medidas que aseguren al hombre las posibilidades de existencia que no puede asegurarse por sí mismo" (Agudo, 2013). Esta procura existencial, afirma Agudo Zamora en la obra citada, se extiende directa o indirectamente a la generalidad de los ciudadanos, materializándose en una serie de prestaciones y medidas al hilo de la coyuntura económica y social, que como nos recuerda Agudo Zamora en reciente monografía, "en áreas centrales propias del Estado social, como pueden ser educación, salud, asistencia social, medio ambiente o cultura", corresponden en España a las Comunidades Autónomas (Agudo, 2019).

Estas consideraciones doctrinales son esenciales para encuadrar el objetivo ambiental que deben tener los Estados en el siglo XXI. Sin duda el medio ambiente, su protección adecuada, con la intervención de los poderes públicos reclamada en el artículo 45 de la Constitución, es un nuevo contenido de ese Estado social, para asegurar el bienestar colectivo e individual, en esa dinámica de protección colectiva, y requiere de esas prestaciones y medidas desde la esfera pública, vinculadas además la protección de la salud colectiva.

En 1978, la constitucionalización del medio ambiente se realiza en nuestra Carta Magna en una doble vertiente: reconociendo un derecho subjetivo y proclamando unos principios ambientales, en el capítulo de los principios rectores de la política económica y social. En efecto, el artículo 45.2 de la Constitución encarga a los poderes públicos "velar por la utilización racional de los recursos naturales" y "defender y restaurar el medio ambiente". Estos principios han de estar vinculados a los fines que el propio precepto establece, "proteger y mejorar la calidad de vida" y ser un "medio adecuado para el desarrollo de la persona".

Algunos estatutos de autonomía recogen entre los objetivos a alcanzar por las instituciones autonómicas, los ambientales. Así, el nuevo Estatuto de Autonomía de Andalucía de 2007 incluye, entre los objetivos básicos de la acción de los poderes públicos propios:

La mejora de la calidad de vida de los andaluces y andaluzas, mediante la protección de la naturaleza y del medio ambiente, la adecuada gestión del agua y la solidaridad 
interterritorial en su uso y distribución, junto con el desarrollo de los equipamientos sociales, educativos, culturales y sanitarios, así como la dotación de infraestructuras modernas (Art. 10.3.7).

Y en su artículo 28 establece, en su apartado primero que

todas las personas tienen derecho a vivir en un medio ambiente equilibrado, sostenible y saludable, así como a disfrutar de los recursos naturales, del entorno y el paisaje en condiciones de igualdad, debiendo hacer un uso responsable del mismo para evitar su deterioro y conservarlo para las generaciones futuras, de acuerdo con lo que determinen las leyes.

En su apartado segundo garantiza

este derecho mediante una adecuada protección de la diversidad biológica y los procesos ecológicos, el patrimonio natural, el paisaje, el agua, el aire y los recursos naturales.

Y, por último, proclama que

todas las personas tienen derecho a acceder a la información medioambiental de que disponen los poderes públicos, en los términos que establezcan las leyes.

En cuanto a la eficacia normativa de los principios ambientales que recoge nuestra Constitución, la primera idea que hay dejar clara es que, como todos los preceptos del Capítulo III del Título I, la eficacia normativa de los principios que contienen el artículo 45 CE (ubicado en ese capítulo) depende de lo dispuesto en el artículo 53.3 CE, que regula la eficacia normativa. Textualmente dice este precepto que

El reconocimiento, el respeto y la protección de los principios reconocidos en el Capítulo Tercero informarán la legislación positiva, la práctica judicial y la actuación de los poderes públicos. Sólo podrán ser alegados ante la jurisdicción ordinaria de acuerdo con lo que dispongan las leyes que los desarrollen.

Hay que recordar una cuestión importante respecto a los principios constitucionales del capítulo III, del Título I. Estos operan como mandatos al legislador y en consecuencia son normas de cobertura constitucional: al asignar obligaciones a los poderes públicos, vinculan su discrecionalidad al modelo de transformación que impone la Constitución (artículo 9.2 y Capítulo III, del Título I de la Constitución). Esta función de cobertura es, en materia ambiental, bastante clara pues la realización de los objetivos constitucionales ambientales supone importantes sacrificios de otros intereses jurídicos.

Importante es el tema de la integración del medio ambiente en lo que se ha venido en denominar "constitucionalismo de lo concreto", como nos recuerda Canosa Usera, 
es decir, la preocupación de los textos constitucionales por las condiciones de vida del ser humano. Esto es el constitucionalismo social que, a diferencia del liberal, se preocupa de lo concreto, de las condiciones de vida del ser humano, lo que supone un acercamiento de las constituciones al ser humano, al ciudadano. En este sentido hay que entender la inclusión de lo ambiental en las constituciones (Canosa, 2000).

Esta necesidad de pegar los textos constitucionales a la realidad y deseos de la ciudadanía ha devenido en una cuestión esencial en el final de la segunda década del siglo XXI, como un elemento político fundamental para la conexión de las acciones públicas y la población, para que veamos en las Constituciones un reflejo jurídico de nuestras propias vidas, de nuestras aspiraciones como ciudadanía responsable.

Nuestro artículo 45 de la Constitución Española, al tiempo que consagra el derecho a "disfrutar del medio ambiente adecuado para el desarrollo de la persona", en el propio primer apartado, in fine, recoge el "deber de conservarlo". Este deber se refuerza con la posible imposición de sanciones penales y administrativas y con la obligación de reparar el daño causado (artículo 45.3). No puede haber ejercicio de un derecho si los titulares del derecho no son, a su vez, sujetos del deber de conservar su objeto, el medio ambiente. Sin la solidaria contribución de todos en la conservación del medio, no es posible el goce del derecho, el ejercicio del derecho al medio ambiente.

La naturaleza de este deber ambiental es la propia de un deber constitucional, puesto que no corresponde con el derecho, sino que es impuesto objetivamente por la Constitución y desarrollado por otras normas de carácter sectorial. En realidad, gran parte de las obligaciones impuestas por el ordenamiento jurídico ambiental provienen de directivas comunitarias, transpuestas a la legislación interna.

Una forma de concretar el deber constitucional de conservación ha sido la inclusión en el Código Penal del llamado delito ecológico, y en la esfera administrativa, con la vigilancia e imposición de sanciones. El artículo 45.3 ofrece cobertura constitucional a todas estas formas de garantizar el objetivo constitucional ambiental.

El Tribunal Constitucional, al abordar el régimen administrativo sancionador en el orden ambiental, entiende que esta materia forma parte de la materia ambiental básica, y, en consecuencia, las normas que la regulan tienen la consideración de básicas. Las comunidades autónomas tan sólo pueden ampliar y mejorar el régimen sancionador fijado por las normas básicas, pero no disminuirlo ni restringirlo (STC 196/1996). Es interesante destacar que tanto el mismo Tribunal, como nuestra Constitución, establecen una conexión entre calidad de vida y protección ambiental, asunto que es muy importante desde el punto de vista axiológico, de los valores, 
como concepto de modelo de Estado y de políticas públicas, y como elemento pedagógico-democrático para la ciudadanía en general y para la juventud en particular, para su compromiso social con el bien común medioambiental.

Es un asunto central, que también aparece, como hemos dicho, en el artículo 45 de nuestra Constitución, aunque no estrictamente como derecho fundamental especialmente protegido, sino como principio rector de la política social y económica, con valor jurídico no de derecho fundamental, sino de principio informador de la legislación positiva, la práctica judicial y la actuación de los poderes públicos, que no implica aplicabilidad o vinculación directa como derecho fundamental, habiendo que estar a la legislación de desarrollo o actuaciones de los poderes públicos a través de programas de actuación.

Considero que, en una próxima y necesaria reforma constitucional, debería garantizarse el derecho al medio ambiente como fundamental y no sólo como principio rector de la política social y económica, de aplicación y desarrollo a la voluntad de los poderes públicos y sin capacidad de la ciudadanía de reclamación de ejercicio efectivo. Debería estar protegido al más alto nivel, en la primera escala de derechos constitucionales, con recurso de amparo incluido, como derecho humano esencial, pues si la máxima protección jurídica de nuestro entorno no hay futuro, estaría en peligro la propia vida.

En cuanto a esta propuesta de reforma constitucional que acabo de formular, desde varios grupos ecologistas se llevó a cabo una campaña pública en ese mismo sentido, con el objetivo y denominación de "blinda tus derechos". En concreto, Mario Rodríguez, director de Greenpeace, mantiene en un artículo de opinión de dicha campaña la necesidad de

el reconocimiento expreso de un derecho fundamental a un medio ambiente adecuado y saludable, que es la tendencia hoy dominante en el Derecho internacional y constitucional comparado. Esto permitiría otorgar al medio ambiente la importancia que merece. Si el medio ambiente se abriera al recurso de amparo, el Tribunal Constitucional construiría una doctrina de este derecho, que fortalecería el debate público y fijaría unos parámetros nuevos desde la lógica de los derechos humanos, vinculantes para los demás tribunales y para los demás poderes públicos (Rodríguez, 2015).

Prosigue el activista que esta reforma constitucional

permitiría abrir la acción popular en el proceso contencioso-administrativo, para mejorar el cumplimiento de la legislación ambiental. Vigilar este cumplimiento no puede recaer sólo en las organizaciones ecologistas. Consideramos que esta defensa ha de abrirse a toda la ciudadanía, pues todas las personas están afectadas por los ataques y riesgos a los intereses ambientales. 
Asimismo, permitiría la exigibilidad de las obligaciones administrativas de tutela del medio ambiente, que se reflejarían en el deber estatal de protección de los derechos humanos, ya consolidado en la jurisprudencia y una profunda revisión de nuestra legislación ambiental, reforzando su función de servicio, en primer lugar, a la dignidad de la persona. Y ello en todos los sectores del Derecho-administrativo, penal y tributario, entre otros--, que deberían tender hacia una mínima unificación bajo la figura del derecho al medio ambiente.

Esas son las razones de la campaña "Blinda tus derechos: cambia el artículo 53", donde se invita a la ciudadanía a que se sume a este esfuerzo, tanto personas individuales como otras organizaciones, movimientos o plataformas que llevan trabajando mucho tiempo en las problemáticas que queremos modificar, y quieran apoyar la petición de una reforma constitucional para poner los derechos humanos en el centro de la Carta Magna. Piden a los partidos políticos que incorporen estas propuestas en sus programas. $Y$ de cara a las nuevas legislaturas, pedirán al Parlamento y Gobierno resultante que lo incorpore en sus prioridades de trabajo. También están en dicha campaña las organizaciones Amnistía Internacional, Greenpeace y Oxfam.

Estoy muy de acuerdo con la propuesta que se formula desde estas organizaciones ecologistas, desde la sociedad civil, en el sentido de actualizar el compromiso medioambiental de nuestra Constitución. De hecho, el programa electoral de Podemos para las elecciones de 2015, así como en las sucesivas elecciones generales posteriores, ya recogía la reforma constitucional para que el derecho al medio ambiente estuviese ubicado entre los derechos fundamentales, directamente invocables y con recurso de amparo. Y en el acuerdo del actual Gobierno de coalición de España el compromiso ambiental está en un lugar destacado y la cartera ministerial de Transición Ecológica tiene ya rango de Vicepresidencia.

A modo de conclusión de este epígrafe, y también como propuesta de futuro, y siguiendo a Nicolás Pérez Sola, Profesor del Departamento de Derecho Público de la Universidad de Jaén, como una fijación del estado de la cuestión, coincido con este autor en que

hemos asistido a lo largo de casi cuarenta años a un proceso de positivación y formalización de un mandato a los poderes públicos para la protección del ambiente en sintonía con los Estados de nuestro entorno. En la mayoría de las ocasiones hay que encontrar en la mera trasposición de las normas comunitarias al ordenamiento interno el surgimiento de un derecho ambiental pero que, desde la perspectiva del artículo 45 CE, tan sólo ha permitido la plasmación de derechos de configuración legal y marcado carácter procedimental, para esgrimir ante los poderes públicos la exigencia de cumplimiento de sus obligaciones en esta materia (Pérez, 2017). 
Prosigue el autor, en su interesante artículo que

tras un breve recorrido por el intento de una construcción doctrinal del derecho al disfrute del medio ambiente como derecho subjetivo de difícil precisión, en cuanto a su contenido y límites, tan solo por aproximación se han podido identificar algunos bienes jurídicos objeto de protección, esencialmente vinculados con las condiciones que hacen posible la calidad de vida de las personas, desde una lectura que consideramos rígida de la distinción tradicional entre derechos y principios rectores, necesitada de superación. Ante este escenario tal vez resultara más oportuno llevar a cabo un cambio de perspectiva y abandonar el intento de centralidad del debate sobre la caracterización como derecho o principio del enunciado del artículo 45 CE.

Por esta razón, concluye,

adquiere mayor relevancia en el momento actual centrar el estudio del artículo 45 CE en torno a los deberes legales que, incorporados por el legislador, tienen un sustento constitucional indiscutible en aquel mandato. Pues consideramos que es la perspectiva del deber la que permite avanzar con mayor precisión en la determinación del objetivo perseguido por el constituyente para su incorporación a nuestra Norma Fundamental. Así, pese a su necesaria configuración legal, se aprecia la existencia de una serie de deberes que se imponen a ciudadanos y poderes públicos, así como una normativa sancionatoria de las conductas que los conculquen.

\section{Como idea final del citado artículo, se expresa que}

prevalece, eso sí, a tenor de la experiencia el mandato a los poderes públicos, la acción positiva como deber de éstos de protección del ambiente que, a través de la integración en nuestro ordenamiento del derecho ambiental europeo, nutre de obligaciones y exigencias a nuestro legislador, y administraciones, dotando a nuestros órganos jurisdiccionales de instrumentos para sancionar en su caso los incumplimientos de este mandato en gran medida exigido por la normativa comunitaria y los convenios internacionales en los que el Estado español ha sido parte. Es en este ámbito donde el control judicial de la actuación de los poderes públicos adquiere un claro protagonismo.

Además, en esa reforma constitucional que propongo, también podría incluirse un nuevo principio constitucional, que ya recoge la actual Constitución de Ecuador, el de "in dubio, pro natura". Esta idea está conectada con la consideración de la protección del medio ambiente como elemento esencial para el bienestar ciudadano, "parcela llamada a convertirse en objeto de la protección del Estado", como mantuvo en su momento, con mucho acierto, el profesor de Derecho Constitucional Manuel José Terol Becerra (Terol, 201 1). Este principio "in dubio, pro natura", creo que tiene además un valor simbólico y pedagógico, muy gráfico y fácil de entender por la ciudadanía en general.

Como elemento final de este epígrafe, quiero dejar constancia de la reflexión del profesor Ángel Valencia Saiz, Catedrático de Ciencia Política de la Universidad de 
Málaga, valorando los 40 años de vigencia del texto del 78 en materia ambiental, que me parece un broche adecuado para concluir este apartado de mi trabajo de tesis doctoral. Considera este autor, como conclusión de ese capítulo de la obra colectiva citada, que

nuestra Constitución planteó hace cuarenta años un tratamiento de lo medioambiental realista y posible, haciéndose eco de las relaciones entre política y medio ambiente en la década de los setenta, pero sin olvidar que en nuestro país esta problemática era aún lejana y, sobre todo, secundaria a un momento político en el que había que edificar la arquitectura constitucional del nuevo orden político democrático. Sin embargo, el desarrollo estatutario muestra, en algún caso, como es el caso del Estatuto andaluz, una sensibilidad ecológica avanzada y que recoge buena parte de los principios del ecologismo político contemporáneo.

Sea como sea, prosigue el autor,

Constitución y Estatutos parece que responden con suficiencia ante el medio ambiente. El problema para la Teoría política verde, en el ámbito de los derechos, es el reconocimiento de derechos al mundo natural ( $y$, por tanto, no solo humanos, por ejemplo, a los animales o a las generaciones futuras). Esa ampliación de la titularidad de los derechos parece, hoy por hoy, difícil. Sin embargo, estamos seguros de que la sociedad española, al igual que nuestra Constitución, como hizo hace cuarenta años, será capaz de estar a la altura de reto del medio ambiente en el futuro (Valencia, 2018).

\section{Algunas conclusiones}

De los elementos y consideraciones expuestas anteriormente en este trabajo, podemos extraer algunas conclusiones y propuestas de futuro.

La primera es que la juventud y las ciudades se han convertido, de hecho, en los principales baluartes de la lucha contra el cambio climático en el final de la segunda década del siglo XXI, todo un síntoma para la esperanza en un mundo mejor cuidado.

La segunda es que nuestro actual artículo 45 de la Constitución, ubicado en el capítulo III del Título I de la Constitución, lo consideramos una protección constitucional insuficiente, pues el medio ambiente debería estar entre los derechos fundamentales, no como principio rector de la política económica y social, dependiente de la política de propuesta legislativa del gobierno de turno. Nuestra norma ambiental principal, el artículo $45 \mathrm{CE}$, aunque mal ubicado sistemáticamente, aparece en el texto por influencia del contexto internacional del momento en relación con 
la cumbre de Estocolmo de 1972, del constitucionalismo social imperante y sus positivas consecuencias sobre todo en Europa.

La tercera es que en una próxima y necesaria reforma constitucional, debería garantizarse el derecho al medio ambiente como fundamental y no sólo como principio rector de la política social y económica, de aplicación y desarrollo a la voluntad de los poderes públicos y sin capacidad de la ciudadanía de reclamación de ejercicio efectivo. Debería estar protegido al más alto nivel, en la primera escala de derechos constitucionales, con recurso de amparo incluido, como derecho humano esencial, pues si la máxima protección jurídica de nuestro entorno no hay futuro, estaría en peligro la propia vida.

La cuarta, es que considero clave que la protección y cuidado del medio ambiente pase a ser, paulatinamente, un asunto relacionado con los valores universales, con el compromiso moral colectivo, con la ética, como un nuevo elemento definidor de ciudadanía global responsable. Textos internacionales como la Encíclica Laudato $\mathrm{Si}^{\prime}$, del Papa Francisco, contribuyen, sin duda, en el proceso de toma de conciencia en ese sentido, tanto en los creyentes y seguidores de la moral católica, como en la ciudadanía global, dada la repercusión de impacto que tienen siempre las palabras y documentos oficiales del Papa.

La quinta es que la protección del medio ambiente se ha ido configurando como un valor, como algo positivo y deseable. Los diferentes sondeos de opinión vienen manifestando que a la gente le preocupa la protección del medio ambiente, la protección de los recursos naturales, y que deberían tomarse medidas por los responsables públicos. Afortunadamente, como hemos expuesto al inicio de este trabajo de investigación, el medio ambiente ha vuelto a la agenda política e institucional.

La sexta es que, aunque la protección de este bien común pareciera que es difusa, tengo claro que en realidad es una responsabilidad compartida de gobernantes, representantes públicos, técnicos, académicos, pero también de la ciudadanía en general, que tenemos en nuestras manos pequeñas acciones con gran incidencia práctica en la protección de dichos valores. Al efecto, es muy necesario animar a la participación general, con información y educación, en la protección del bien común medioambiental. Como expresaba el lema de Naciones Unidas en la Conferencia de Madrid de diciembre de 2019, es "tiempo de actuar".

Y la séptima, a modo de conclusión y propuesta final, es que posiblemente, como concluyo en mi Tesis Doctoral, 
la tercera década del siglo XXI será el momento en que deba surgir el Estado ecologista, como una profundización y especial compromiso del Estado social. La estructura estatal, como organización racional del poder político, que empezó siendo un Estado liberal de Derecho, que evolucionó hacia el Estado democrático y, finalmente, pensando en el bienestar material general, llegó a ser un Estado social en el siglo XX, quizá en la tercera década del presente siglo, esa estructura política Estado ha de pensar en el entorno de vida que nos rodea, con carácter transversal y prioritario, y convertirse así, en una cuarta dimensión, en un Estado ecologista.

\section{Bibliografía}

Agudo ZAMORA, M. (2013). La protección multinivel del Estado social. Tirant Lo Blanch.

- (2017) "El principio de no regresividad de los derechos sociales en el ordenamiento constitucional español". Revista de Derecho Político, UNED ( $\left.{ }^{\circ} 100\right)$.

- (2019). Reforma constitucional y Estado autonómico. Tecnos.

Bolaño PIÑEIRO, M. C. (coord.) (2018). Nuevas perspectivas del Derecho Ambiental en el siglo XXI. Marcial Pons/Departamento de Medio Ambiente, Planificación Territorial y Vivienda del Gobierno Vasco.

Canosa Usera, R. (2000) Constitución y medio ambiente. Dykinson.

EsPINOSA GONZÁlEZ, A. (2015) Tesis Doctoral: Derechos humanos y medio ambiente: el papel de los sistemas europeo e interamericano, Universidad Carlos III.

Font Galán, J. I. (2019) Lección de despedida de mi vida académica "El terrible derecho de propiedad y los bienes comunes de la humanidad". Ediciones Don Folio.

Gómez Puerto, A. B. (2020) Tesis Doctoral: La protección constitucional del medio ambiente. Implicación de la ciudadanía en el cuidado del bien común medioambiental. Universidad de Córdoba.

IBÁÑ̃ez MÉNDEZ, I. (2003) "Los poderes públicos y la defensa del medio ambiente". Observatorio Medioambiental.

JAQUENOD DE ZsÖGÖN, S. (1996). Iniciación al derecho ambiental. Dykinson.

López MeNUDO, F. (2005) "El derecho a la protección del medio ambiente" en Derecho Ambiental de Andalucía, Tecnos. 
López Ramón, F. (2005) "El medio ambiente en la Constitución española". Revista de Derecho Urbanístico, 2005.

- (2018) "La formación del ordenamiento ambiental" en El medio ambiente 1978-2018. Ministerio para la Transición Ecológica.

Martín Mateo, R. (2003) Manual de Derecho Ambiental. Aranzadi.

Nogueira LóPEZ, A. (2018) "El demediado derecho a un medio ambiente adecuado", en España constitucional (1978-2018), Volumen III. Centro de Estudios Políticos y Constitucionales.

- (2019). "La huella ecológica. El establecimiento de indicadores ambientales y su significación para el Derecho". Revista Catalana de Dret Ambiental, ( $\left.n^{\circ} 1\right)$.

Rodríguez, M. (2015) "El derecho constitucional al medio ambiente". El País.

Ruiz Robledo, A. (1993) “Un componente especial de la Constitución Económica. La protección del medio ambiente". Revista Andaluza de la Administración Pública, 1993.

Terol Becerra, M. J. (2000). "Acerca del carácter más razonable que racional de la jurisprudencia constitucional relativa al medio ambiente". Revista Española de Derecho Constitucional ( $\left.{ }^{\circ} 59\right)$.

- (2009) "Sobre el estudio jurídico-constitucional del medio ambiente". Revista de Derecho Político (n 75-76).

- (2011) "Aproximación al contenido de un Derecho Constitucional al medio ambiente". Estudios de Deusto: revista de la Universidad de Deusto ( $\left.{ }^{\circ} 2\right)$.

Valencia SaIz, A. (2018) "Medio ambiente: perspectiva de Teoría política", en España constitucional (1978-2018), Volumen III. Centro de Estudios Políticos y Constitucionales.

VON DeR LeYeN, U. (2019) "Un Pacto Verde Europeo", en Orientaciones políticas para la próxima comisión europea 2019-2024. Oficina de Publicaciones Oficiales de la Comisión Europea.

- (2019) "Un Pacto Verde para Europa y el planeta". El País. 